\title{
EFFECT OF WHITE TEA EXTRACT IN VITRO AGAINST CARIOGENIC AND PERIODONTAL BACTERIA
}

\author{
ELZA IBRAHIM AUERKARI*, ANTONIUS WINOTO SUHARTONO
}

\author{
Department of Oral Biology, Faculty of Dentistry, Universitas Indonesia, Jakarta, 10430, Indonesia. Email: eauerkari@yahoo.com
}

Received: January 2018, Revised and Accepted: November 2018

\section{ABSTRACT}

Objective: This work aimed to evaluate the in vitro antimicrobial properties of white tea maceration extract against pathogenic oral bacteria Streptococcus mutans (serotype F), Porphyromonas gingivalis (strain ATCC 33277), and Actinobacillus actinomycetemcomitans (phenotype A); the properties of this product were also tested against non-pathogenic Streptococcus sanguis (ATCC 10556) for comparison.

Methods: A maceration extract was made from white tea collected from West Java, and the infusion was prepared at concentrations of 5-80\%. The selected strains of each microbial species were cultured under anaerobic conditions, and equalized standard dilutions of the cultured bacteria were used for testing. Dilution and diffusion tests were conducted to quantify the antimicrobial properties of white tea extract (WTE) against the bacteria.

Results: The dilution test results showed a minimum inhibitory concentration of $40 \%$ of WTE against S. mutans, P. gingivalis, and A. actinomycetemcomitans and $80 \%$ against S. sanguis. The minimum bactericidal concentration was $80 \%$ for all tested bacterial strains.

Conclusion: The diffusion test results showed higher inhibition with increasing extract concentration; however, the difference between concentrations of $40 \%$ and $80 \%$ was small or negligible, except for A. actinomycetemcomitans. These results imply the clear, acute antimicrobial effect of WTE against the tested oral anaerobic pathogens in vitro. Considering that these effects were concentration dependent and that white tea has the highest content of antimicrobial phenolic compounds among all grades of (green) tea, white tea or WTE may be useful for inhibiting the growth of pathogens involved in the development of caries and/or periodontal disease.

Keywords: White tea extract, Antimicrobial, Cariogenic bacteria, Periodontal bacteria.

(c) 2018 The Authors. Published by Innovare Academic Sciences Pvt Ltd. This is an open access article under the CC BY license (http://creativecommons. org/licenses/by/4. 0/) DOI: http://dx.doi.org/10.22159/ijap.2018.v10s1.35

\section{INTRODUCTION}

Tea produced by the aqueous infusion of processed leaves of the evergreen shrub Camellia sinensis $L$. is a common beverage worldwide. In addition to the taste and flavor, the popularity of tea may stem from its mildly stimulating effect, which is mainly due to the presence of approximately $50 \mathrm{mg}$ of caffeine per cup. However, before being widely consumed as a beverage, tea was originally used for medicinal purposes. In particular, green tea has been reported to inhibit the growth of pathogenic microbes including species belonging to the genera Staphylococcus, Salmonella, Shigella, Vibrio, Bordetella, Clostridium, Helicobacter, and Pseudomonas [1-13]. Such antimicrobial effects have also been indicated against cariogenic bacteria and other oral pathogens [14-22]. However, there has been some disagreement on the capacity of tea to inhibit the growth of susceptible and resistant bacterial species due to differences in microbial strains and the types and concentration of tea extracts [1-3,9-22].

Nevertheless, there is a wide range of aqueous plant extracts that are traditionally used for medicinal purposes due to the antimicrobial benefits of various compounds that the plants likely use for innate defenses [23-26].

The antimicrobial properties of tea are thought to be largely due to polyphenolic compounds, which account for approximately $30 \%$ of the dry weight of the buds and immature leaves that are picked and processed. The simplest and most important of these compounds are isoflavonoids, which are also known as catechins and account for approximately $10 \%$ of the dry weight of ordinary green tea. The catechins of tea mainly consist of epicatechins, epigallocatechins, epicatechin gallates, and epigallocatechin gallates (EGCGs), which occur at concentrations of up to $1 \mathrm{mg} / \mathrm{mL}$ of tea [21]. Among these compounds, EGCG is characteristic to tea and is generally rare or absent in other plants [23]. Although large polyphenolic molecules, such as tannic acid, can be toxic and carcinogenic, this is not the case for the catechins of tea, such as EGCG, which appears to be mainly responsible for the potential benefits of tea. White tea, which is a grade of green tea produced from silvery white, very young leaf buds, has the highest concentration of catechins among all grades of green tea. This work aims to evaluate the antimicrobial properties of a macerated white tea extract (WTE) against select oral bacteria, particularly cariogenic Streptococcus mutans, Porphyromonas gingivalis, and Actinobacillus actinomycetemcomitans, which are important pathogens in periodontal disease. For comparison, the antibacterial effects of WTE were evaluated for Streptococcus sanguis, which is a common but more neutral streptococcal species of the oral cavity.

\section{METHODS}

\section{Preparation of WTE}

White tea was obtained from PT Perkebunan Nusantara VIII Cisaruni Field, West Java, Indonesia, and maceration extraction was conducted at the LIPI Chemical Laboratory (Tangerang, Banten, Indonesia). In brief, $202 \mathrm{~g}$ of dried white tea was soaked in $2 \mathrm{~L}$ of $70 \%$ ethanol for $24 \mathrm{~h}$. The solution was then filtered and evaporated at $50^{\circ} \mathrm{C}$, with the final stage occurring in a vacuum oven. The process was repeated twice for the residual matter. The resulting dry WTE was used in subsequent experiments as an aqueous solution containing $0.8 \mathrm{~g} / \mathrm{mL}$ of the extract in water plus dimethyl sulfoxide (DMSO). For the experiments, this $80 \%$ baseline solution was further diluted as required with water containing DMSO.

\section{Bacterial culture}

The bacterial species selected for culturing were $S$. mutans serotype F, S. sanguis strain ATCC 10556, P. gingivalis strain ATCC 33277, and 
Table 1: Dilution test results of various WTE concentrations

\begin{tabular}{llll}
\hline Medium/concentration & $\begin{array}{l}\text { S. mutans } \\
\text { serotype F }\end{array}$ & $\begin{array}{l}\text { S. sanguis } \\
\text { ATCC 10556 }\end{array}$ & $\begin{array}{l}\text { A. actinomycetemcomitans } \\
\text { phenotype A }\end{array}$ \\
\hline C (+) no WTE & + & + & + \\
C (-) no bacteria (\%) & - & - & - \\
5 & + & + & + \\
10 & + & + & + \\
20 & + & + & + \\
40 & - & + & - \\
80 & - & - & - \\
\hline
\end{tabular}

(-): No bacterial growth (clear), (+): Bacterial growth observed (turbid). S. mutans: Streptococcus mutans, P. gingivalis: Porphyromonas gingivalis, A. actinomycetemcomitans: Actinobacillus actinomycetemcomitans, S. sanguis: Streptococcus sanguis, WTE: White tea extract

Table 2: Inhibition zone sizes at various WTE concentrations

\begin{tabular}{lllll}
\hline Concentration of WTE (\%) & $\begin{array}{l}\text { S. mutans serotype } \\
\text { F (mm) }\end{array}$ & $\begin{array}{l}\text { S. sanguis ATCC } \\
\mathbf{1 0 5 5 6}(\mathbf{m m})\end{array}$ & $\begin{array}{l}\text { A. actinomycetemcomitans } \\
\text { phenotype A (mm) }\end{array}$ & $\begin{array}{l}\text { P. gingivalis ATCC } \\
\mathbf{3 3 2 7 7}(\mathbf{m m})\end{array}$ \\
\hline 5 & 2 & 2 & 2 & 3 \\
10 & 2.5 & 6 & 6 & 4 \\
20 & 7 & 8 & 6 & 4 \\
40 & 15 & 16 & 9 & 8 \\
80 & 17 & 17 & 14 & 8 \\
\hline
\end{tabular}

S. mutans: Streptococcus mutans, P. gingivalis: Porphyromonas gingivalis, A. actinomycetemcomitans: Actinobacillus actinomycetemcomitans, S. sanguis: Streptococcus sanguis, WTE: White tea extract

A. actinomycetemcomitans phenotype A (standard). Each bacterial sample was transferred into a test tube containing $\mathrm{NaCl}$ solution, and the test tubes were shaken until a homogeneous mixture was obtained. Each strain of bacteria was grown in thioglycolate broth medium and incubated in a gastight anaerobic jar at $37^{\circ} \mathrm{C}$ for $72 \mathrm{~h}$. The optical microscopy of Gram-stained bacterial samples was used to confirm the culture results. After culturing, the test tube turbidity level was adjusted to McFarland standard level 1 , which corresponds to a cell concentration of approximately $3 \times 10^{8} \mathrm{CFU} / \mathrm{mL}$ for all bacterial strains. Each bacterial suspension was diluted with $\mathrm{NaCl}$ solution to 1:2000 (approximately $1.5 \times 10^{5} \mathrm{CFU} / \mathrm{mL}$ ) for inoculation.

\section{Dilution and diffusion testing}

For dilution testing, $0.2 \mathrm{~mL}$ of each equalized and diluted bacterial solution was transferred into test tubes containing the selected concentrations of WTE with DMSO. As a positive control, $0.2 \mathrm{~mL}$ of each bacterial solution was inoculated into $4 \mathrm{~mL}$ of thioglycolate broth medium with DMSO. WTE at a $50 \%$ concentration without bacterial inoculation was used as a negative control. The test tubes were incubated in an anaerobic jar for $72 \mathrm{~h}$ at $37^{\circ} \mathrm{C}$ and then evaluated for the presence or absence of bacterial growth. After comparison with the negative control, turbidity in the test tube was taken to indicate bacterial growth $(+)$, whereas the lack of turbidity indicated no bacterial growth (-). To confirm the absence of bacterial growth in the clear test tubes, sampled contents were also cultured on agar plates. The minimum inhibitory concentration (MIC) was defined as the lowest tested concentration to prevent bacterial growth. The minimum bactericidal concentration (MBC) was defined as the concentration that killed $99.9 \%$ of the inoculated bacteria. For the disk diffusion test, each equalized and diluted bacterial seed was poured slowly and evenly on an agar plate that was tilted slightly to remove any excess, and the samples were incubated at $37^{\circ} \mathrm{C}$ for $15 \mathrm{~min}$. Round, $6 \mathrm{~mm}$, sterilized, filter paper disks were soaked in the WTE solutions of preselected concentrations $(5 \%, 10 \%, 20 \%, 40 \%$, and $80 \%$ ) and allowed to dry before placing the discs on the seeded agar plates. The plates were then incubated at $37^{\circ} \mathrm{C}$ for $72 \mathrm{~h}$ in an anaerobic jar, and the mean diameters of the inhibition zones around the paper disks were measured.

\section{RESULTS}

The effects of various WTE concentrations in the dilution test for S. mutans, S. sanguis, P. gingivalis, and A. actinomycetemcomitans are summarized in Table 1 . The results confirmed that sufficient concentrations of WTE had antimicrobial effects against the tested microbes. The MIC was $40 \%$ against S. mutans, $P$. gingivalis, and
A. actinomycetemcomitans and $80 \%$ against $S$. sanguis. The MBC was $80 \%$ for all tested bacteria.

The results of the disk diffusion test are summarized in Table 2 . In general, all tested extract concentrations showed some effect (diffusion zones) on the tested microbial strains. An increase in the inhibition zone suggested that the inhibitory effect increased with the WTE concentration. The strongest inhibition was found at a concentration of $80 \%$. However, the increase in extract concentration was attenuated toward higher concentrations. The difference between the concentrations of $40 \%$ and $80 \%$ was small or negligible, except for A. actinomycetemcomitans, which still exhibited a considerable increase in inhibition zone size at a WTE concentration of $40-80 \%$. At $80 \%$, the inhibition zone size was $>10 \mathrm{~mm}$ for all bacteria, except $P$. gingivalis, which had a slightly smaller inhibition zone size of $8 \mathrm{~mm}$.

\section{DISCUSSION}

The results of the disk diffusion test showed distinct inhibition zones even at the lowest test WTE concentration (5\%) against all tested oral bacteria. Complete inhibition required 40\% WTE concentration for all pathogenic strains, that is, S. mutans serotype F, P. gingivalis strain ATCC 33277, and A. actinomycetemcomitans phenotype A. Although an even higher (80\%) concentration was needed to inhibit S. sanguis (strain ATCC 10556), this bacterial species is not pathogenic but is rather a commensal microbe of the oral cavity. It may also be worth noting that no WTE concentration between $40 \%$ and $80 \%$ was used. By considering only the tested pathogenic bacteria, a rather modest concentration of WTE appeared to provide significant acute inhibition in vitro. The size of the inhibition zone was relatively extensive in the diffusion tests and ranged from 4 to $8 \mathrm{~mm}$ at a $20 \%$ concentration (Table 2); however, zone size is not necessarily a unique indicator of growth inhibition. The diffusion test results showed that the diffusion zone size tended to sharply increase at WTE concentrations of up to $40 \%$, with relatively little change at higher concentrations, except for A. actinomycetemcomitans, which showed a continuous increase in zone size at WTE concentrations between $40 \%$ and $80 \%$ (Table 2).

The active compounds of the WTE were not further analyzed in terms of chemical composition but presumably contained a high fraction of catechins, which are known to be largely responsible for the antimicrobial properties of green and white tea [13-24]. 
The dilution test results showed an MIC of 40\% WTE for the cariogenic species S. mutans (serotype F), P. gingivalis (strain ATCC 33277), and A. actinomycetemcomitans (phenotype A); P. gingivalis and A. actinomycetemcomitans are commonly implicated in periodontal disease. The corresponding MIC was $80 \%$ for the nonpathogenic streptococcal species S. sanguis (strain ATCC 10556). The MBC was $80 \%$ for all tested strains. The diffusion test results showed increasing inhibition with the extract concentration, except for A. actinomycetemcomitans, which showed a small difference in inhibition between the concentrations of $40 \%$ and $80 \%$.

These results support the existing body of evidence on the benefits of green tea on oral health [3-21]. The results are also comparable with the reported effect of green tea extract on other types of pathogenic microbes such as $S$. aureus, $P$. aeruginosa, and C. albicans, which cause skin infections. At concentrations of $5 \mathrm{mg} / \mathrm{mL}$ of dried hydroethanolic extract dissolved in DMSO, the application of the extract produced an inhibition zone of $>10 \mathrm{~mm}$, which increased to approximately $20 \mathrm{~mm}$ with a concentration of $10 \mathrm{mg} / \mathrm{mL}$, similar to that of standard antibiotics [27]. For such purposes, stability and penetration of the active compounds can also matter [28].

This evidence implies that the active compounds of green and white teas have broad-spectrum antimicrobial properties when present in sufficient concentrations. In general, the results of the present study imply the clear, acute antimicrobial effect of WTE against the tested oral anaerobic pathogens in vitro. Considering that this effect is concentration dependent and that white tea has the highest content of antimicrobial phenolic compounds among all grades of green tea, WTE could be useful for inhibiting the growth of pathogens involved in caries and/or periodontal disease. Further studies are needed to evaluate the parallel effect of WTE in vivo with long-term exposure corresponding to the habitual use of white tea or WTE. Given that white tea will remain available in smaller quantities than other main grades, it could also be worth it to consider other means of extracting active compounds, such as EGCG, from minimally processed bulk flush of tea plants.

\section{CONCLUSION}

The results of this study showed the clear, acute antimicrobial effect of WTE against the tested oral anaerobic pathogens in vitro. Considering that the effect is concentration dependent and that white tea has the highest content of antimicrobial phenolic compounds among all grades of (green) tea, white tea or WTE may be useful for inhibiting the growth of pathogens involved in the development of caries and/or periodontal disease. Further studies are needed to investigate these effects in vivo under long-term applications and with extracted active compounds to address cost efficiency.

\section{CONFLICTS OF INTEREST}

All authors declare that they have no conflicts of interest.

\section{REFERENCES}

1. Hamilton-Miller JM. Antimicrobial properties of tea (Camellia sinensis L.). Antimicrob Agents Chemother 1995;39:2375-7.

2. Toda M, Okubo S, Hiyoshi R, Shimamura T. The bactericidal activity of tea and coffee. Lett Appl Microbiol 1989;8:123-5.

3. Toda M, Okubo S, Ohnishi R, Shimamura T. Antibacterial and bactericidal activities of Japanese green tea. Nihon Saikingaku Zasshi 1989;44:669-72.

4. Toda M, Okubo S, Hara Y, Shimamura T. Antibacterial and bactericidal activities of tea extracts and catechins against methicillin resistant Staphylococcus aureus. Nihon Saikingaku Zasshi 1991;46:839-45.

5. Toda M, Okubo S, Ikigai H, Suzuki T, Suzuki Y, Hara Y, et al. The protective activity of tea catechins against experimental infection by vibrio cholerae O1. Microbiol Immunol 1992;36:999-1001.

6. Ahn YJ, Kawamura T, Kim M, Yamamoto T, Mitsuoka T. Tea polyphenols: Selective growth inhibitors of Clostridium spp. Agric Biol Chem 1991;55:1425-6.

7. Ahn YJ, Sakanaka S, Kim M, Kawamura T, Fujisawa T, Mitsuoka T. Effects of green tea extracts on growth of intestinal bacteria. Microb Ecol Health Dis 1990;3:335-8.

8. Fukai K, Ishigami T, Hara Y. Antibacterial activity of tea polyphenols against phytopathogenic bacteria. Agric Biol Chem 1991;55:1895-7.

9. Hara Y, Ishigami T. Antibacterial activities of tea polyphenols against foodborne pathogenic bacteria. J Jpn Soc Food Sci Technol 1989;36:996-9.

10. Hara Y, Watanabe M. Antibacterial activity of tea polyphenols against Clostridium botulinum. J Jpn Soc Food Sci Technol 1989;36:951-5.

11. Horiuchi Y, Toda M, Okubo S, Hara Y, Shimamura T. Protective activity of tea and catechins against Bordetella pertussis. J Jpn Assoc Infect Dis 1992;66:599-605.

12. Stoicov C, Saffari R, Houghton J. Green tea inhibits helicobacter growth in vivo and in vitro. Int J Antimicrob Agents 2009;33:473-8.

13. Almajano MP, Carbo R, Jimenez JA, Gordon MH. Antioxidant and antimicrobial activities of tea infusions. Food Chem 2008;108:55-63.

14. Tsunoda T, Yamazaki T, Mukai I. Oral Preparations Containing Catechins for Periodontitis and Halitosis Control. Japanese Patent JP $03218320 ; 1991$.

15. Hattori M, Kusumoto IT, Namba T, Ishigami T, Hara Y. Effect of tea polyphenols on glucan synthesis by glucosyltransferase from Streptococcus mutans. Chem Pharm Bull (Tokyo) 1990;38:717-20.

16. Kawamura J, Takeo T. Antibacterial activity of tea catechin to Streptococcus mutans. J Jpn Soc Food Sci Technol 1989;36:463-7.

17. Muroi H, Kubo I. Combination effects of antibacterial compounds in green tea flavor against Streptococcus mutans. J Agric Food Chem 1993;41:1102-5.

18. Onishi M, Ozaki F, Yoshino F, Murakami Y. Experimental evidence of caries preventive activity of nonfluoride component of tea. J Dent Health 1981;31:158-61.

19. Onishi M, Shimura N, Nakamura C, Sato M. A field test on the caries preventive effect of tea drinking. J Dent Health 1981;31:13-9.

20. Otake S, Makimura M, Kuroki T, Nishihara Y, Hirasawa M. Anticaries effects of polyphenolic compounds from Japanese green tea. Caries Res 1991;25:438-43.

21. Sakanaka S, Kim M, Taniguchi M, Yamamoto T. Antibacterial substances in Japanese green tea extract against Streptococcus mutans, a cariogenic bacterium. Agric Biol Chem 1989;53:2307-11.

22. Ryu E, Blenden DC, Wendall D. The inhibition of growth of selected bacteria by incorporating powdered tea in the medium. Int J Zoonoses 1982;9:73-7

23. Stagg GV. Tea=the elements of a cuppa. Nutr Bull 1980;29:233-45.

24. Senthilkumar SR, Sivakumar T, Arulmozhi KT, Mythili N. Gas chromatography-mass spectroscopy evaluation of bioactive phytochemicals of commercial green teas (Camellia sinensis) of India. Asian J Pharm Clin Res 2015;8:278-82.

25. Ambarwati NSS, Elya B, Malik A, Hanafi M. Phytochemical and antimicrobial studies on Garcinia lattissima Miq. Fruit extract. Asian J Pharm Clin Res 2017;10:230-2.

26. Agrawal PK. Antimicrobial and phytochemical analysis of leaf extract of medicinal fruit plants. Asian J Pharm Clin Res 2016;9:131-6.

27. Kulandhaivel M, Palaniswamy M. In vitro antimicrobial activity of Camellia sinensis and Myristica fragrans against Staphylococcus aureus, Pseudomonas aeruginosa, Candida albicans. Int J Pharm Biol Arch 2012;3:604-9.

28. Ramadon D, Pramesti SS, Anwar E. Formulation, stability test and in vitro penetration study of transethosomal gel containing green tea (Camellia sinensis L. Kuntze) leaves extract. Int J Appl Phamr 2017;9:91-6. 